\title{
Open to debate
}

It is confusing to both students and clinicians in obstetrics and gynaecology that much is open to debate.

The findings of the Term Breech Trial ${ }^{[1]}$ are quite clear: regardless of the experience of the obstetrician, regardless of the normality of the pregnancy or of the normal progress of labour, a $1 \%$ chance remains of entrapment of the aftercoming head, along with its consequences. Yet there are still those who question the analysis, citing, for example, individual cases that did not exactly fit enrolment, and some clinicians continue to offer vaginal breech delivery.

The findings of the Women's Health Initiative (WHI) Study, ${ }^{[2]}$ in fact a combination of three randomised controlled trials (RCTs) and one observational study on the use of hormone replacement therapy (HRT), show that HRT may produce more harm than benefit, and an increased mortality due to stroke (myocardial infarction was increased in the oestrogen/progestogen arm). Many have questioned these findings, as many question the advanced age at patient enrolment, and continue with prescription of HRT. The WHI and the Million Women Study ${ }^{[3]}$ created intense debate on HRT use.

The findings of studies may often be contradictory or seemingly contradictory, forcing debate, or there may be seeming contradiction within a single study. Magnesium sulphate administered to a mother at risk of preterm delivery has been shown to provide neuroprotection. Yet, in a landmark Australasian study, the clear benefit seen in stillbirth and early neonatal death in the treatment arm was followed by the absence of an advantage in neurological milestones in the long-term follow-up. ${ }^{[4]}$ Difference produces uncertainty, and so debate. A meta-analysis of the four main randomised controlled trials (RCTs) on neuroprotection showed different findings, and a number of outcomes not reaching significance, but an overall continued recommendation for magnesium sulphate remains. ${ }^{[5]}$

Contradictory findings have also affected the debate on the use of progesterone as primary prevention for preterm labour. Vaginal progesterone has been recommended for 15 years as a treatment for those at high risk for premature delivery ${ }^{[6]}$ Many articles have supported this. However, in February 2016, the largest RCT to date, the OPPTIMUM study, ${ }^{[7]}$ was published, and among 1228 randomised patients treated from 22 - 24 weeks to 34 weeks, there was no benefit in gestation at delivery, neonatal intensive care admission or any analysis of morbidity or mortality, and in fact, a concern was raised for a possible negative effect on neonatal renal function. This created debate.

A recommendation for or avoidance of an intervention is based on a balance of cost and benefit. Cost may be measured in dollars. The cost of progesterone increased 2 000\% when the American Food and Drug Administration announced its benefit in preventing premature labour in 2011 (primarily citing the long-published 2003 National Institute of Child Health and Development study). ${ }^{[8]}$ This affected any cost/benefit calculation to any individual or healthcare system.

The cost of an intervention may be measured as harm, demonstrated by morbidity, great or small, or even by mortality. The frequency and magnitude of actual benefit or harm are important. This is applicable to HRT use: frequent symptomatic benefit is compared with the risk of breast cancer - potentially a $1 \%$ risk after 10 years - potentially diminished with oestrogen alone, and increased by additional progestogen, and a risk of coronary thrombosis or stroke, measured in cases per 10000 woman-years of use. $^{[2,3]}$ These comparative benefits and costs are a matter for debate.

Individual benefit and harm may differ in different patients, identified in different 'subgroups'. In HRT use, the frequency of the occurrence of rare thrombotic events is diminished by the exclusion of patients with dyslipidaemias, obesity, hypertension or a family history of thrombosis, and smokers. So significant is the effect on incidence of the exclusion of these at-risk groups that this resulted in the disappearance of HRT as a primary prevention of myocardial infarction (with concern for thrombosis for those at risk). To have made such a suggestion 20 or 25 years ago would have been considered heresy, and any request to hold such a debate at that time would have been met with little sympathy. Yet already, 25 years ago, the subgroup analysis had been performed in the observational studies.

This process of subgroup analysis in estimating advantage and disadvantage may, as shown, affect the way we consider literature evidence, and how it applies or does not apply to an individual patient requesting or being considered for a specific treatment.

Hannah et al., ${ }^{[1]}$ the authors of the Term Breech Trial, attempted to deal with subgroups in order to remove all confounding variables.

Those who wish to read the OPPTIMUM study may think, 'But what about the subgroup of patients with a short cervix who are at risk of premature labour?' Looking closely, they will see that the study analysed the use of progesterone specifically in those with a cervix $<2.5 \mathrm{~cm}$, and showed no benefit. ${ }^{[7]}$

This creates debate, because patients with a short cervix are specifically recommended for progesterone by the American College of Obstetricians and Gynecologists, ${ }^{[9]}$ and this has not been corrected.

A meta-analysis by Romero et al. ${ }^{[10]}$ in 2016 criticises the OPPTIMUM finding on short-cervix patients, and says that the study for this group was not 'powered' to reach this conclusion. And so the debate moves on. A recommendation for progesterone persists.

Close scrutiny of evidence therefore may require it to be broken down into individual parts. Scrutiny of the Cochrane database may show that an overall or meta-analysis conclusion ultimately rests on the decisive influence of a study of 67 patients, in a more impressive assembly of 1200 .

The debate over benefits can go beyond the recognition of statistical significance, which may be misleading, and may give credit where there is little due. One such attempt at correction is the 'number needed to treat' analysis. An outcome may have statistical significance, but the less credulous will note that the number needed to treat indicates that 60 patients need to be treated to see the benefit - for every 60 patients treated, 59 will not. If the benefit is great, large numbers are accepted. There is one such calculation for the use of magnesium sulphate in neuroprotection, where the number needed to treat is calculated as $41{ }^{[5]}$ For progesterone, it has been calculated at $10-19 \cdot{ }^{[10]} \mathrm{A}$ clinician must weigh such a chance of success when considering/debating cost and side-effects. 
The more radical the treatment, the greater the importance of debate regarding those who will not benefit, and the greater the need that they should be identified. A Wertheim hysterectomy for cervical cancer is for those with stage 1 disease; those who require later radiation for positive or close margins or positive lymph nodes receive no survival benefit at all from the preceding radical hysterectomy, but only its complications, stress and cost.

For this reason - following debate - stage 1 disease was modified and divided into the smaller $1 \mathrm{~b} 1(\leq 4 \mathrm{~cm})$, with a greater chance of effective cure by surgery alone, and the larger $1 \mathrm{~b} 2(>4 \mathrm{~cm})$. A similar debate, but for choice of the abdominal route v. the vaginal, resulted in Wertheim's dismissal and vilification. He temporarily lost the argument. Why? Because his senior, Schauta, believed that the cost, in this case mortality, exceeded any treatment advantage.

Today, a debate rages over the possible survival disadvantage of laparoscopic radical hysterectomy for operable cancer of the cervix, compared with traditional laparotomy. A $10 \%$ disadvantage to laparoscopy in disease-free survival has been demonstrated. ${ }^{[1]}$

Radicality is not required for a medical process to cause harm. Even tests can result in harm. Some may experience harm from a test that others do not. Of patients tested for 'high-risk' human papilloma viruses (HPVs), either as an adjunct to Pap smear testing or alone, $90 \%$ in a population at age 35 may test negative, and $10 \%$ positive.

Those testing negative see benefit from reassurance that they do not harbour the viruses; their subsequent tests are less frequent; there is less cost to themselves and the healthcare system. But those who test positive may experience an exaggerated fear of imminent cancer (the internet will describe HPV as 'highly oncogenic'; this is easily translated), and also a fear of a sexually transmitted infection (sexual transmission is presumed), and subsequent harmful effects on a relationship and sexual health. The psychological cost to HPVpositives and the test's benefit in cancer prevention/cost-saving can be debated. To see a single patient devastated by the result is enough to question the benefit.

Tests are not merely evaluated on their potential, unintentionally, to do harm, but on their accuracy. Accuracy, and so applicability, is often debated. A strong negative predictive value in a test excludes the condition, and saves unnecessary and costly, and sometimes harmful, observation and intervention. A strong positive predictive value is required to have an impact on disease morbidity or even mortality. A test may have both.

In this edition, a test to identify pre-eclampsia is discussed. ${ }^{[12]}$ Preeclampsia has a high incidence in South Africa. Its cost in morbidity and mortality is great, both by underdetection and, possibly, by overdiagnosis. The article acknowledges that the previous benefit seen from using this test in countries in which the incidence and the healthcare systems are different from our own must be examined wherever the test's benefit and cost is to be evaluated. This remains, at present, here, open to debate.

Debate in medicine is permanent. New evidence may challenge existing beliefs, or may in turn itself be challenged.

Uncertainty may be resolved or explained by discussion with colleagues whose open minds have followed arguments and evidence evolution. Flexibility of protocols may acknowledge alternative opinions. In the end, a clinician must face a patient and offer honest and thorough counselling, explain advantages and disadvantages as best as they are understood, and take a decision, or assist in a decision.

As debate continues, students and juniors in training may possess knowledge that others, including examiners, may lack, since experience tells us that medical knowledge is sometimes available before it is widely recognised.

\section{William Edridge}

Editor

william.edridge@gmail.com

S Afr J Obstet Gynaecol 2018;24(2):34-35. DOI:10.7196/SAJOG.2018.v24i1.1416

1. Hannah ME, Hannah WJ, Hewson SA, Hodnett ED, Saigal S, Willan AR. Planned caesarean section versus planned vaginal birth for breech presentation at term: A randomised multicentre trial. Term Breech Trial Collaborative Group. Lancet 2000;356(9239):1375-1383.

2. Hays J, Hunt JR, Hubbell FA, et al. The Women's Health Initiative recruitment methods and results. Ann Epidemiol 2003;13(9Suppl):S18-77. https://doi.org/10.1016/s1047-2797(03)00042-5

3. Beral VC, Reeves G, Bull D. Breast cancer and hormone-replacement therapy in the Million Women Study. Lancet 2003;362(9382):419-427. https://doi.org/10.1016/S0140-6736(03)14596-5.

4. Doyle LW, Anderson PJ, Haslam R, Lee KJ, Crowther C, for the Australasian Collaborative Trial of Magnesium Sulphate (ACTOMgSO4) Study Group. School-age outcomes of very preterm infants after antenatal treatment with magnesium sulfate v. placebo. JAMA 2014;312(11):1105-1113. https://doi.org/10.1001/jama.2014.11189

5. Crowther CA, Middleton PF, Voysey M, et al., for the AMICABLE group. Assessing the neuroprotective benefits for babies of antenatal magnesium sulphate: An individual participant data meta-analysis. PLoS Med 2017;14(10):e1002398 https://doi.org/10.1371/journal.pmed.1002398

6. Meis PJ, Klebanoff M, Thom E, et al, for National Institute of Child Health and Human Development Maternal-Fetal Medicine Units Network. Prevention of recurrent preterm delivery by 17 alpha-hydroxyprogesterone caproate. N Engl J Med 2003;348(24):2379-2385. https://doi. org/10.1056/NEJMoa035140

7. Norman JE, Marlow N, Messow CM, et al., for the OPPTIMUM study group. Vaginal progesterone prophylaxis for preterm birth (the OPPTIMUM study): A multicentre, randomised, double-blind trial. Lancet 2016;387(10033):2106-2116. https://doi.org/10.1016/S0140-6736(16)00350-0

8. National Institute of Child Health and Human Development. FDA Approves Drug to Reduce Preterm Birth Risk. https://www.nichd.nih.gov/newsroom/releases/021611-FDA-approves-drug (accessed 11 November 2011).

9. Committee on Practice Bulletins - Obstetrics, The American College of Obstetricians and Gynecologists. Practice Bulletin no. 130: Prediction and prevention of preterm birth. Obstet Gynecol 2012;120(4):964-973. https://doi.org/10.1097/AOG.0b013e3182723b1b

10. Romero R, Nicolaides KH, Conde-Agudelo A, et al. Vaginal progesterone decreases preterm birth $\leq 34$ weeks of gestation in women with a singleton pregnancy and a short cervix: An updated meta-analysis including data from the OPPTIMUM study. Ultrasound Obstet Gynecol 2016;48(3):308-317. https://doi.org/10.1002/uog.15953

11. Practice Update. Minimally Invasive v. Abdominal Radical Hysterectomy for Cervical Cancer. https://www.practiceupdate.com/content/minimally-invasive-vs-abdominal-radicalhysterectomy-for-cervical-cancer/75599/37/1/1 (accessed 5 May 2018)

12. Matjila M, Anthony J, Vatish M, et al. Consensus statement on the implementation of the sFlt-1/ PIGF ratio in women with suspected pre-eclampsia. S Afr J Obstet Gynaecol 2018;24(2):61-65. https://doi.org/10.7196/SAJOG.2018.v24i2.1411 